\title{
From "haves" to "have nots": Developmental declines in subjective social status reflect children's growing consideration of what they do not have
}

\author{
Rebecca Peretz-Lange (SUNY Purchase) \\ Teresa Harvey (Boston University) \\ Peter R. Blake (Boston University)
}

In press at Cognition

Word count: 7,156 words

Corresponding author:

Rebecca Peretz-Lange, Ph.D.

Psychology Department

SUNY Purchase

rebecca.peretzlange@purchase.edu 


\title{
HAVES TO HAVE NOTS
}

\begin{abstract}
Subjective social status (SSS), or a person's view of their own socioeconomic status, has important consequences for social cognition and wellbeing, yet little is known about its development before adolescence. Previous research finds that SSS declines during childhood. We sought to replicate this finding, and also to extend it by investigating what aspects of children's reasoning drive this developmental decline. To do so, we assessed four- to ten-yearold children's SSS using a MacArthur Ladder Task $(n=377)$, which has been validated for use with children in this age range. We then assessed children's open-ended rationales for their SSS judgments. Results indicated that SSS declined over child development, replicating previous work. We also confirmed that this decline corresponded with improvements in SSS accuracy; young children overestimated their SSS relative to their objective SES, but were relatively accurate by age ten. Moreover, trends in children's rationales revealed that developmental shifts in both SSS and SSS accuracy corresponded with children's references to what they do not have, but not with references to what they do have, nor with references to any particular status cues (e.g., houses, lifestyle). Thus, children may increasingly consider what they lack to determine their status. Implications for self-evaluation and social cognition are discussed.
\end{abstract}

Keywords: Social status, cognitive development, self-evaluation, social comparison. 


\section{From "haves" to "have nots": Developmental declines in subjective social status reflect children's growing consideration of what they do not have}

The United States, along with much of the world, is experiencing a rise in wealth inequality (Zucman, 2019). How do children determine their place in this increasingly steep socioeconomic hierarchy? A person's conception of their own position in a socioeconomic hierarchy has been termed "subjective social status" (Jackman \& Jackman, 1973; APA Task Force on Socioeconomic Status, 2007). Subjective social status, or SSS, has a variety of impacts on wellbeing and social cognition. However, little is known about how SSS develops, the nature of any systematic biases in children's SSS, or what information children use to ascertain their SSS. The present study aims to address these gaps. In particular, we investigate (1) how SSS changes with age, and (2) how children reason about their social status, and (3) whether any developmental changes in this reasoning explain developmental changes in children's SSS.

\section{Implications of SSS}

A wide literature indicates that SSS predicts wellbeing. Among adults, lower SSS predicts lower overall health (Singh-Manoux et al., 2005; Anderson et al., 2012), reduced life expectancy (Marmot, 2004), more depressive symptoms (Hoebel et al., 2017), and higher levels of aggression (Greitemeyer \& Sagioglou, 2016). These relations have been observed in adolescence as well (Goodman et al., 2015; Rivenbark et al., 2019; Quon \& McGrath, 2015). Critically, although a low objective SES presents very real barriers to health and wellbeing, subjective social status predicts wellbeing and longevity even when objective SES is controlled for (Marmot, 2004; Singh-Manoux et al., 2005). For example, a study of over 10,000 adolescents 
found that SSS predicted obesity even after controlling for objective SES (Goodman et al., 2001). Despite these important consequences, little research has explored SSS among children.

Research does indicate that children are highly attuned to socioeconomic status and attend to a rich variety of status cues, including occupation (Bigler et al., 2003; Enesco \& Navarro, 2003), material wealth (e.g., houses, Olson et al., 2012; Shutts et al., 2016); clothing (Ramsey, 1991), free time (Shutts et al., 2016), and choice of friends (Heck et al., 2020). Children use these status cues to inform their judgments. For example, by age four, children judge higher-status individuals as nicer (Li, Spitzer, \& Olson, 2014), more competent (Shutts et al., 2016; Sigelman, 2012), more generous (Ahl et al., 2019; Ahl \& Dunham, 2019), and betterliked by others (Mookherjee \& Hogan, 1981; Shutts et al., 2016), and prefer higher-status friends (Ahl \& Dunham, 2019; Horwitz et al., 2014). Within experimental contexts, children are also sensitive to how equally resources are distributed (Kirkland et al., 2020, 2021) and whether they are resource-rich or -poor compared to others (Kirkland et al., 2021; LoBue et al., 2010). Yet, it is not yet well-understood how children determine their SSS in real-world contexts.

In sum, children are sensitive to socioeconomic status information from a young age, and their ideas about status have important implications both for their wellbeing and for social cognition. However, research has primarily focused on children's judgments of others' status, rather than their own status, or SSS. The literature that does focus on SSS has primarily studied adolescents and adults. Little is known about SSS in childhood, the focus of the present study.

\section{Developmental declines in SSS}

Three recent studies have examined SSS in childhood. Together, these studies indicate that SSS declines over development. In particular, they show that preschoolers tend to view 
themselves as high-status (Mandalaywala, Tai, \& Rhodes, 2020); that by 10 years of age, children's SSS is relatively accurate (Mistry et al., 2015); and that SSS declines with age, even across diverse cultures (Amir et al., 2019). Across all three studies, researchers assessed SSS using adaptations of the MacArthur Scale, a ten-rung ladder task commonly used to assess SSS among adults and adolescents (e.g., Goodman et al., 2001; Martin-Storey et al., 2018). We review these studies in detail below.

Mistry and colleagues (2015) assessed 10- to 12-year-olds' SSS by asking them to place their families on a 10-rung ladder representing a wealth hierarchy. Children's SSS ratings correlated with objective SES indicators, such as household income and parental education level, as well as with parents' SSS ratings. Thus, although younger children were not tested in this study, by age ten, children appear to estimate their SSS relatively accurately.

In a second, recent study, Mandalaywala, Tai, and Rhodes (2020) assessed 3.5- to 6-yearolds' SSS as part of a battery of tasks. In a rope task (an adaptation of ladder-based tasks), children were asked to place their families on a vertical arrangement of pegs, alongside a rope, representing a social status hierarchy. Researchers told children that people at the top "have lots of toys and new clothes," while to people at the bottom "don't have any," referencing status cues that would be familiar to young children. Children were asked where they belonged on the rope. Responses were close to ceiling, indicating that young children tended to view themselves as high-status. However, the researchers noted that they were unable to collect SES information from families, and therefore that the accuracy of children's high SSS ratings was unclear. Critically, though, these high SSS ratings were not due to children's confusion about the task: Children's ratings of other children on the rope task were not at ceiling, and correlated with other status measures used in the study (e.g., a house-matching task). Thus, participants did not 
universally overestimate social status, but rather overestimated their own social status in particular. The researchers called for future investigations into why young children tend to overestimate their SSS, as well as direct investigations into the accuracy of children's SSS.

Finally, important work by Amir and colleagues (2019) established the validity and reliability of ladder-based SSS assessments for children. They used the ten-rung ladder task to assess SSS among 4- to 18-year-old children across four different cultural contexts: The US, India, Argentina, and two different regional communities of the indigenous Shuar people in the Ecuadorean Amazon. Their results showed that SSS ratings correlated with responses to other social comparison measures, and that test-retest reliability was high even after a week had passed. Researchers also found that SSS declined with age at similar rates in each population. As in the previous study, researchers were not able to collect objective SES measures, and thus could not determine the accuracy of participants' SSS.

Together, these three studies validate SSS assessment in childhood using ladder-type tasks, and they also demonstrate developmental declines in SSS. In particular, findings suggest that young children (3.5- to 6-year-olds) tend to view themselves as high-status, and that older children (10- to 12-year-olds) tend to judge their SSS somewhat accurately. However, the accuracy of SSS among children younger than age ten has not yet been assessed.

In the present study, we aimed to replicate this developmental decline in SSS, and we also aimed to extend this research in two important ways: Primarily, we sought to understand why this developmental decline takes place. As an initial inquiry into this question, we analyzed children's open-ended rationales for their SSS judgments. This approach follows a tradition in cognitive science of using children's explanations as a meaningful window into early cognitive processes (Rhodes, 2014; Wellman, 2011). We assessed developmental shifts in children's 
rationales, and we investigated how any such shifts in children's reasoning corresponded with shifts in SSS. In doing so, we aimed to shed initial light on the mechanisms underlying developmental declines in SSS. As a secondary aim, we also collected household socioeconomic information to speak to the accuracy of children's SSS. Evidence that young children's SSS declines over development strongly suggests that SSS accuracy might increase over development. We sought to confirm this in the present study, and also to identify how developmental shifts in children's reasoning accounted for shifts in SSS and in SSS accuracy.

\section{What might drive developmental declines in SSS?}

Given young children's sensitivity to the wealth and status of others, children's tendency to overestimate their own status is somewhat surprising. What might account for this tendency, and for its developmental decline? Below, we review three (non-exhaustive) possible cognitive mechanisms in children's reasoning that could underlie this early tendency toward SSS overestimates. The present study will enable us to adjudicate between these possibilities.

One possibility is that young children might simply hold a broadly inflated view of themselves. A large related literature on children's evaluations of their competence shows that children tend to overestimate their own abilities and future performance on tasks, despite more accurately estimating others' abilities and performance (Brummelman \& Thomaes, 2017; Ruble, Eisenberg, \& Higgins, 1994; Ruble et al., 1992; Thomaes, Brummelman, \& Sedikides, 2017). This inflated view of one's competence may reflect "wishful thinking," or young children's inability to distinguish between their ideal self and their actual self (Harter, 2012, Schneider, 1998); it may help children maintain self-esteem (Cvencek, Greenwald, \& Meltzoff, 2016; Trzesniewski, Kinal, \& Donnellan, 2010); and it may reflect environments and parental 
messages that emphasize positivity and encourage self-congratulatory behavior (see Cimpian, 2017 for a review). These mechanisms might also drive children's inflated SSS.

Another possibility is that the particular status cues children use to evaluate their socioeconomic status might shift over development in ways that support more accurate SSS. Indeed, some research finds developmental shifts in the cues children use to evaluate others' status. For example, Rauscher, Friedline, and Banerjee (2017) asked preschoolers to imagine a family with a lot of money, and asked them, "how could you tell they have a lot of money?". In this longitudinal study, they found that as children got older they increasingly focused on lifestyle differences rather than on material wealth (e.g., amount of toys, money itself) (see also Leahy, 1981; 1983; Martin-Storey et al., 2018). Exploring development beyond preschool, Sigelman (2012) asked 6-, 10-, and 14-year-old children why a man was rich or poor. She found that children increasingly cited the man's occupation and education as they grew older. Together, this literature suggests that children might increasingly focus on more indirect cues to status, such a lifestyle, occupation, and education, rather than on direct cues such as money itself or material belongings, to determine others' social status. Thus, it is possible that there might also be shifts in the cues children use to determine their own family's social status, and that as children start to attend to more indirect status cues, their SSS becomes more accurate.

A final possibility is that young children's SSS overestimates might reflect an early tendency not to engage in social comparison, or to tend not to evaluate themselves through comparison with their actual or hypothetical peers. Traditionally, research has found that young children tend not to spontaneously engage in social comparison, particularly "upward" social comparison toward those who are "above" them (Boggiano \& Ruble, 1979; Ruble et al., 1994). For example, when evaluating their own performance on a task, children tend to ignore their 
peers' superior performance (Boggiano \& Ruble, 1979; Pomerantz et al., 1995; Ruble et al., 1980) and overestimate their own future performance (Cimpian, 2010; Schneider, 1998; Smiley \& Dweck, 1994). However, more recent research on this topic is mixed, suggesting that children do engage in social comparison under particular circumstances (Magid \& Schulz, 2015; Rhodes \& Brickman, 2008) and that any early tendency not to engage to social comparison may reflect the nature of children's environments rather than cognitive deficits (Cimpian, 2017). This existing research primarily focuses on children's social comparisons of competence, rather than of status, but it is possible that similar processes are involved across both domains. Young children's tendency to view themselves as high-SSS may reflect an early tendency not to engage in upward social comparison, or to not consider ways in which they could be higher-status.

\section{The present study}

Subjective social status plays an important role in wellbeing and in social cognition, yet little is known about how it develops before the adolescent years. Recent research shows that SSS declines across childhood and that it can be assessed using ladder-type tasks similar to those used with adolescents and adults. However, existing research has not (1) incorporated objective SES data to confirm that these SSS declines correspond with improvements in SSS accuracy. Moreover, (2) research has not investigated why SSS declines take place, or explored whether they reflect shifts in the reasoning children employ to determine their social status. We aimed to address these gaps in the present study.

First, how do SSS and SSS accuracy change over development? We focused on four- to ten-year-old children to capture developmental shifts between the period when children's SSS is near ceiling (i.e., the preschool years, see Mandalaywala et al., 2020) and the years when it is 
more accurate (i.e., early adolescence, see Mistry et al., 2015). We used the MacArthur ladder task used in previous work, and expected to replicate the finding that SSS declines over development (Amir et al., 2019). Extending this research, we also assessed the accuracy of children's SSS, which has not yet been assessed in children younger than ten years old. Specifically, we evaluated the accuracy of children's SSS judgments (i.e., judgments of their families' status relative to their neighborhood) by comparing them to families' objective "relative social status" (i.e., families' income relative to the median household income in their neighborhood). This approach follows previous neighborhood-based definitions of relative social status used in the adult SSS literature (Luttmer, 2005; Cheung \& Lucas, 2016; Quon \& McGrath, 2015). We aimed to confirm that SSS grows increasingly accurate over development as children less often overestimated their social status.

Second, how do children determine their social status? How does children's reasoning shift over development, and can these shifts account for age-related shifts in SSS? Research has not explored rationales for SSS in children under age ten. As an initial investigation into this topic, we probed children's open-ended rationales for their SSS to avoid suggesting particular cues or modes of reasoning. Our coding scheme tracked the types of cues children referenced in their rationales (following Mistry et al., 2015, who coded adolescents' SSS rationales), as well as how many times children mentioned having and not having something (following Martin-Storey et al., 2018, also with adolescents). These codes would enable us to adjudicate between different possible forms of reasoning children might employ to determine their social status.

We imagined several distinct possible trends in children's rationales, which would indicate different cognitive mechanisms underlying the predicted age-related changes in SSS. One possibility is that young children may overestimate their SSS because they broadly view 
themselves favorably. If this is the case, then young children's rationales should be more positive globally, including more have codes and fewer don't-have codes, than older children's. Alternatively, if young children overestimate their SSS because they rely on particular (misleading) status cues, then rationales should cite different cues over development, and agerelated shifts in cues should account for age-related shifts in SSS. As a final alternative, if young children overestimate their SSS because they fail to consider what they do not have (i.e., because they struggle with upward social comparison), their rationales should include fewer don't have codes, but not necessarily more have codes, and shifts in don't have codes should account for shifts in SSS. As all of these possibilities have empirical support, we made no a priori prediction about which of these patterns of results would emerge.

\section{Method}

\section{Participants}

A total of 377 four- to ten-year-old children (47.5\% male, $52.5 \%$ female; mean age $=7.6$ years; age range $=4.0$ years -10.9 years) participated in this study. Data collection was stopped once a prespecified date arrived, rather than when a particular sample size was reached. However, post-hoc power analyses confirmed that this sample size was sufficient to detect medium-small $(d=.4)$ age-related shifts in binary outcome variables (i.e., status cues; determined by a power analysis for binary logistic regression with $\alpha=.006$ given multiple comparisons) as well as continuous outcome variables (i.e., SSS; determined by a power analysis for linear regression with $\alpha=.05$ ) at a power level of .8. Participants were recruited from local science museums $(n=91)$, parks $(n=81)$, and a family database at a university lab $(n=205)$. Recruitment took place in a United States city. 
Demographic information was collected through a demographic form, though completion of the form was optional as per IRB requirements. Of the participants who reported their racial background ( $82.6 \%$ of participants), $54.4 \%$ were white and $28.2 \%$ were of color. Participants of color were predominantly Black (6.6\%), Asian or Pacific Islander (6.9\%), and multiracial (9\%). Of the participants who reported their annual household income (85.5\% of participants), responses ranged across the eight income brackets presented, from $<\$ 20,000 /$ year $(2.9 \%$ of participants) to $>\$ 250,000 /$ year $(9 \%$ of participants). The median household income bracket selected was \$100,000-150,000/year. As such, the median household income (MHI) of our sample was higher than the MHI of families with children in the U.S. $(\$ 78,000$, see Kids Count Data Center), but was consistent with the MHI of families with children in the state where recruitment took place $(\$ 111,800$, see Kids Count Data Center), as well as with prior work on SSS in early adolescence (e.g., Mistry et al., 2015).

We also computed participants' objective "Relative SES," (RSES), or their household status relative their surrounding community. Computing objective RSES would later allow us to determine the accuracy of participants' SSS estimates of their families' status relative to their surrounding neighborhoods. To compute RSES, we compared each family's income bracket (1-8 ordinal income brackets) and subtracted the income bracket of their zip code's Median Household Income (the same 1-8 ordinal brackets). We then added 6 to produce a $0-11$ range comparable to the 1-10 range of participants' SSS judgments. Higher RSES scores represented a higher socioeconomic status relative to one's neighborhood, while lower RSES scores represented the opposite. Note that there were 262 participants ( $70 \%$ of our sample) whose families provided both their household income backet and their zip code (130 different zip codes were provided), enabling us to calculate their RSES. 


\section{Procedure \& Materials}

Participants first completed an SSS task and then provided rationales for their choices on the task. All procedures and research instruments were been approved by the [blinded] Institutional Review Board [protocol details blinded for review].

First, participants were introduced to a picture of a ten-rung ladder (see Figure 1). The experimenter explained, "Imagine that this ladder is like your neighborhood. There are some families in your neighborhood that have the most money and food, the biggest houses, and whose parents have the best jobs. Imagine that those families are here [pointing to rung 10]. There are other families who have the least money and food, the smallest house or no house, and whose parents have the worst jobs or no jobs. Imagine that those families are here [points to rung 1]. Now think about your own family. Where would you put your family on this ladder?"

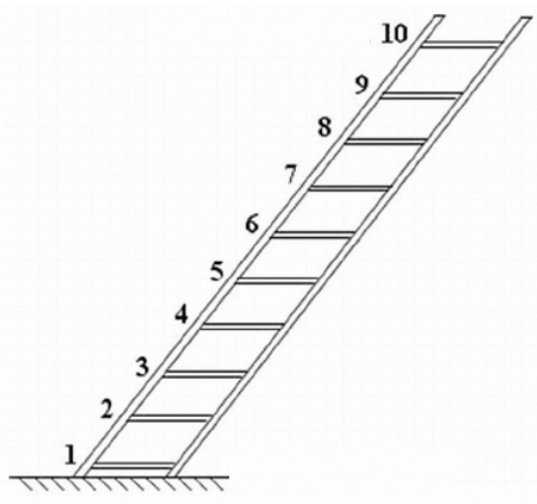

Figure 1. Ladder presented to participants.

Next, participants were asked to provide rationales for their choices. The experimenter asked, "Why do you think your family is there?" and reprompted participants ("Any other reasons?") until they were done. Rationales were transcribed and were later coded for content.

\section{Coding}

Coding of SSS Accuracy. To determine the general accuracy of participants' SSS judgments, we subtracted participants' RSES (computed as described above) from their SSS. 
This yielded accuracy scores ranging from -6 to 8 , with positive scores indicating a greater overestimate, lower scores indicating a greater underestimate, and scores closer to zero indicating a more accurate estimate. While not perfectly precise, this approach provided a general indication of participants' SSS accuracy.

Coding of Rationales. The coding scheme captured two dimensions of participants' rationales: First, it captured participants' use of eight different status cues: Money, houses, material belongings, food, parent occupation, parent education, neighborhood, and lifestyle. Note that some of these cues were included in the verbal prompt, while others were not. Children were coded as mentioning ("1") or not mentioning ("0") each cue. These codes were also summed to represent the total number of different types of cues mentioned. Second, the coding scheme also captured the number of references children made to things their family has or can do ("have"

Table 1. Examples of rationales and how they were coded.

\section{Rationale}

We have a lot of food, my mom and dad have a lot of money, we have games, we also have electronics, and we save money by eating leftovers.

We are going to Mexico this summer and you have to be pretty rich to do that.

Because my family has a job and we have a pretty decent house and we don't have a lot of money but we have a decent amount of money and I wouldn't consider myself, my family rich because we don't have like a really big house. We live in like a condo so that's why I would say we're here.

Because we have a nice house and we have food, we have money but not like a bunch, we have regular money and all the stuff but not higher like rich people.

Because like, my family's not like rich but like we have a lot of money and every other house is like the size of our house.

\section{Codes}

Status cues: Money, material belongings, food Haves: 4; Don't haves: 0

Status cues: Lifestyle Haves: 1; Don't haves: 0

Status cues: Money, house, parent occupation Haves: 3; Don't haves: 2

Status cues: Money, house, food Haves: 4; Don't haves: 2

Status cues: Money, house, neighborhood

Haves: 1; Don't haves: 1 
codes) and things they don't have or can't do ("don't have" codes). In most cases, these codes referred to things of value (e.g., "we have good jobs, "we don't have a big house"), making "have" codes generally positive and "don't have" codes generally negative ${ }^{1}$. Rationales were coded by the first author and second authors. Reliability was strong, both overall (Cohen's $\kappa=$ $.85)$ as well as among individual cue codes ( $\kappa$ coefficients ranged from .82 for Lifestyle codes to 1.0 for Parent Education codes). See Table 1 for examples of rationales' coding.

\section{Results}

Analyses focused on (1) developmental changes in SSS and SSS accuracy, and (2) developmental changes in rationales, and (3) whether any age-related changes in rationales accounted for age-related changes in SSS or SSS accuracy.

\section{Developmental changes in SSS and SSS Accuracy}

First, a linear regression was conducted to determine whether SSS judgments varied by participant age. The analysis revealed that age accounted for a significant portion of the variance in SSS judgments $\left(F(1,375)=11.5, p<.001, R^{2}=.03\right)$, with each additional month in age associated with a .02 decrease in SSS, as illustrated in Figure 2. These results replicated prior findings that SSS declines across the childhood years.

Next, to investigate how age predicted SSS accuracy, we regressed accuracy scores ( 0 to 11) onto participant age (in months) in another linear regression. As illustrated in Figure 3a, this model was significant, $F(1,260)=13.0, p<.001$, and revealed that age accounted for $4.7 \%$ of the variance in SSS accuracy scores. Children's accuracy scores tended to be positive overall,

\footnotetext{
${ }^{1}$ See Section 2a in the Supplementary Materials for exploratory analyses supporting this point.
} 
indicating overestimation, but this tendency decreased over development; in particular, a onemonth increase in age was associated with a .03 decrease in accuracy score $(S E=.008)$. Children's SSS judgments reached accuracy around 9 years of age. In sum, although young children tended to overestimate their SSS, this tendency decreased over development as children's SSS judgments grew more accurate, confirming our predictions.
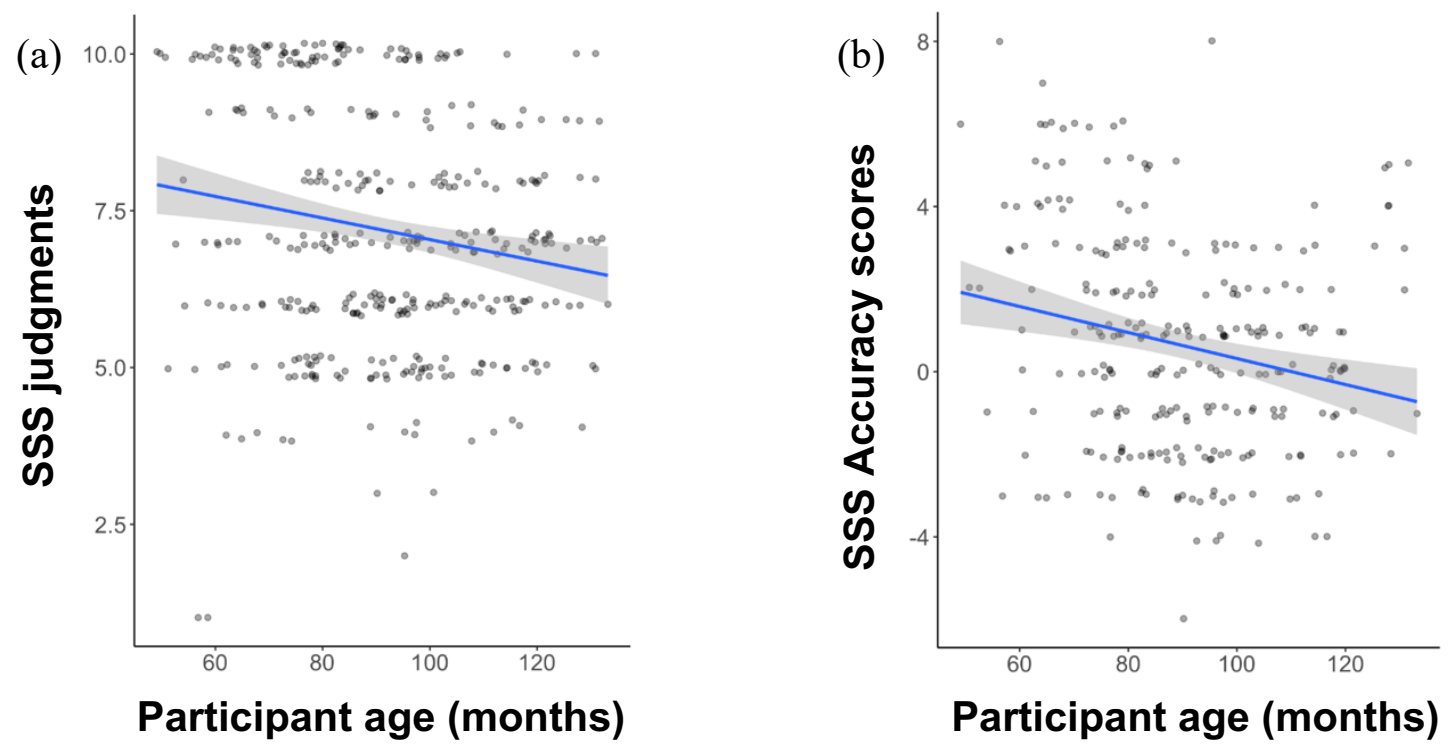

Figure 2. Estimated marginal means of (a) Subjective Social Status (SSS) judgments (1-10 scale) and (b) SSS accuracy scores (further above zero = greater overestimate) by participant age. Band represents $95 \% \mathrm{CI}$.

\section{Developmental changes in rationales}

Recall that each rationale was coded for the specific status cues it referenced (e.g., houses, parent occupation, lifestyle), as well as for the number of times it referenced having or not having something. We analyzed developmental shifts in each set of codes separately. We expected to find either developmental (a) declines in children's overall positive self-evaluations, (b) shifts in status cues, or (c) increases in consideration of what children did not have.

Status cues. First, we investigated whether cue use shifted over development. Regression analyses were conducted to investigate how cues varied over development, again using age in 
months as a continuous predictor variable. An initial linear regression analysis revealed that the total number of cues referenced increased significantly over development $(F(1,375)=17.1, p<$ .001 ), indicating that participants' rationales grew richer in general, referring to a broader variety of cues, as participants grew older. Next, to determine whether there was a developmental increase in the use of any particular cue, a series of eight binomial logistic regressions were conducted to determine how the presence or absence of each cue varied as a function of age (again, with age in months as the continuous predictor variable in each regression). The analyses revealed that, adjusting for multiple comparisons (Bonferroni correction, $\alpha=.006$ ), only the increase in neighborhood cues represented a significant age-related shift (Wald $Z=3.3, p<$ $.001) .^{2}$ Overall, we did not find strong evidence that the particular cues children used to infer SSS shifted substantially over development, with the exception of neighborhood cues.

“Haves" and "don't haves." Next, two Poisson regression analyses 3 investigated how "haves" (i.e., the number of "have" codes, range: 0-5) and "don't haves" (i.e., the number of “don't have" codes, range: 0-4) shifted over development, respectively. Both regression models were significant (Haves: $X^{2}(1)=17.8, p<.001$; Don't haves: $\left.X^{2}(1)=13.4, p<.001\right)$, revealing significant age-related increases in both "haves" $(B=1.01)$ and "don't haves" $(B=1.02)$. Thus, as participants grew older, their rationales referred to more things they had, as well as more things they did not have. This finding was inconsistent with the prediction that participants' selfevaluations simply become broadly less positive over development. If this were the case, then rationales would include fewer "haves" and more "don't haves" over development. 4

\footnotetext{
${ }^{2}$ See Sections $2 b$ and $2 c$ in the Supplementary Materials for further exploratory analyses of status cue codes.

${ }^{3}$ Poisson regressions were used, as this approach is appropriate for modeling zero-inflated count data. (The frequency of " 0 " codes is evident in Figure 3.). Note, however, that linear regressions revealed similar results).

${ }^{4}$ See Section $2 d$ in the Supplementary Materials for further exploratory analyses related to rationales' positivity.
} 


\section{Relations between rationales and SSS}

Finally, we sought to determine how developmental shifts in rationales accounted for developmental shifts in SSS and SSS accuracy. Our analyses focused first on the status cue codes and then on the "have" and "don't have" codes. We expected age-related declines in SSS to correspond with either (a) declines in children's overall positive self-evaluations, (b) shifts in status cues, or (c) increases in consideration of what one does not have.

Status cues. First, a linear regression was conducted to investigate whether variance in cue use predicted variance in SSS judgments. A regression including all eight cues as binary predictors did not account for significant variance in participants' SSS judgments $(p=.67)$. So, variance in cue use, even when taken altogether, did not predict variance in SSS judgments. Moreover, although children tended to use a greater variety of cues as they grew older, a regression indicated that the number of different cues referenced did not predict SSS judgments when age was held constant $(p=.19)$. In sum, neither which cues were used, nor how many cues were used accounted for significant variance in SSS. These results did not support the possibility that shifts in SSS reflected age-related shifts in the use of status cues.

“Haves” and “don't haves.” Next, regression analyses were conducted to determine how "haves" and "don't haves" respectively accounted for variance in SSS and SSS accuracy. A Poisson regression of SSS onto both "haves" and "don't haves" indicated that only "don't haves" accounted for significant variance in $\operatorname{SSS}\left(X^{2}(1)=14.1, p<.001\right)$, while "haves" did not $\left(X^{2}(1)=\right.$ $1.60, p=.21$ ), as shown in Figure 3. Thus, variance in SSS corresponded with variance in "don't haves," but not with variance in "haves." Similarly, regression analyses were conducted to determine whether "haves" and "don't haves" accounted for variance in SSS accuracy. A linear regression of SSS accuracy score onto both "haves" and "don't haves" was significant, $F(2,259)$ 
$=11.4, p<.001$, and revealed that variance in "don't haves" accounted for significant variance in SSS accuracy $(b=-.85, S E=.19, p<.001)$ while variance in "haves" did not $(p=.051)$, echoing the asymmetry reported above. ${ }^{5}$

(a)

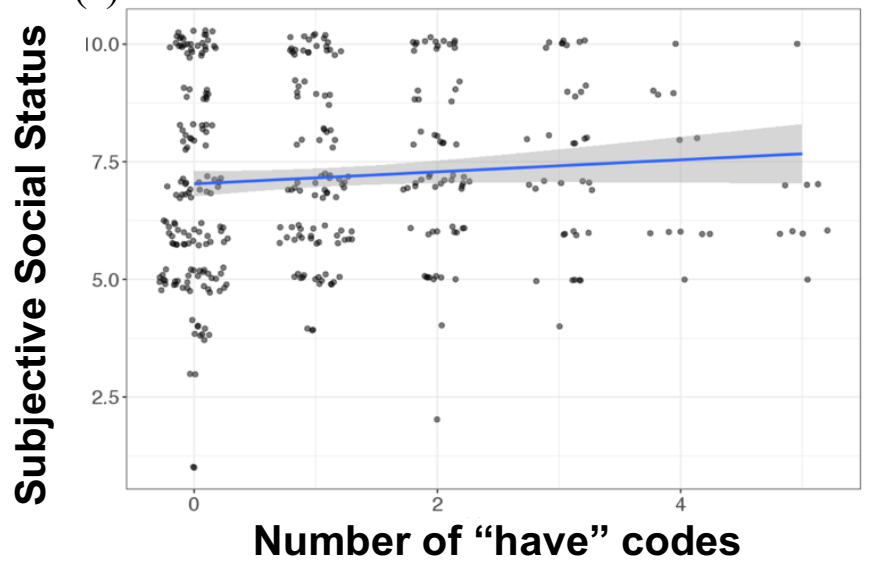

(b)

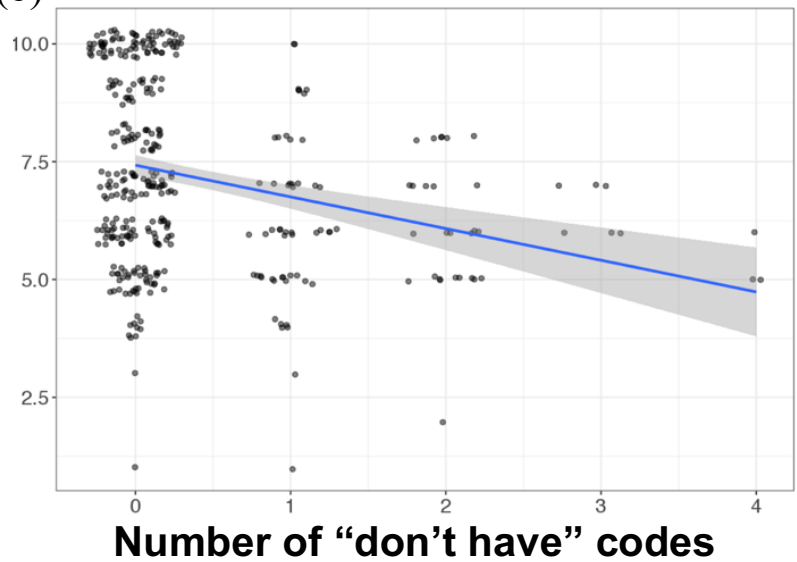

Figure 3. (a) Nonsignificant relation between "haves" and SSS, and (b) significant negative relation between "don't haves" and SSS. Bands represent 95\% CI.

Finally, we examined the degree to which "haves" and "don't haves" respectively mediated the relationship between age and SSS by employing a multiple mediation model. We employed a bias-correcting bootstrapping method, an approach that avoids parametric assumptions and is recommended for estimating indirect effects, particularly in smaller samples (Fritz \& MacKinnon, 2007). The 95\% confidence intervals computed over 1,000 bootstrapped samples were used to estimate each indirect effect. As illustrated in Figure 4, this analysis revealed that "don't haves" significantly mediated the relation between age and SSS ( $B=-0.04$, $S E=.001, p=.001)$, but "haves" $\operatorname{did} \operatorname{not}(p=.054)$. The analysis also revealed a significant

\footnotetext{
${ }^{5}$ See Sections 2e and $2 \mathrm{f}$ of the Supplementary Materials for exploratory analyses confirming the robustness of these effects.
} 
direct effect of age on SSS ( $B=-.16, S E=.006, p=.005)$, indicating that "haves" and "don't haves" only partially mediated the relation between age and SSS.

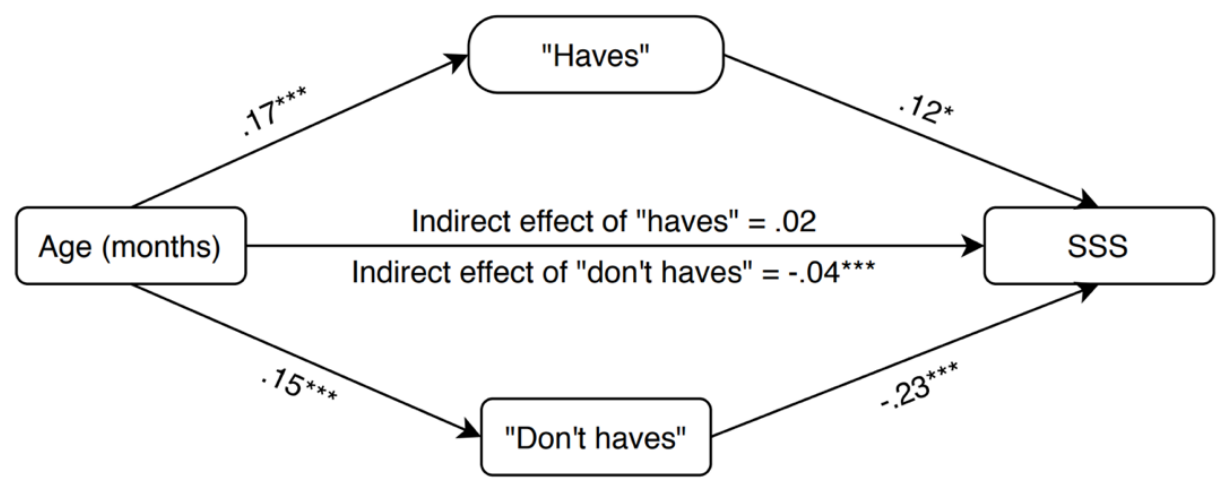

Figure 4. Summary of the effects on SSS through "have" and "don't have" codes in participants" rationales. Paths are labeled with their beta coefficients. Asterisks represent significance at the $.05(*), .01(* *)$, and .001 levels $(* * *)$.

A second mediation model, illustrated in Figure 5, explored relations between age, SSS accuracy, and "haves" and "don't haves," using the same approach. Like the previous model, this model revealed that "don't haves" significantly mediated the relation between age and SSS accuracy $(B=-.04, S E=.003, p=.02)$, while "haves" did not significantly mediate this relation $(p=.2)$. The analysis also revealed a significant direct effect of age on SSS accuracy $(B=-.16$, $S E=.008, p=.007)$, indicating that "haves" and "don't haves" only partially mediated the relation between age and SSS accuracy.

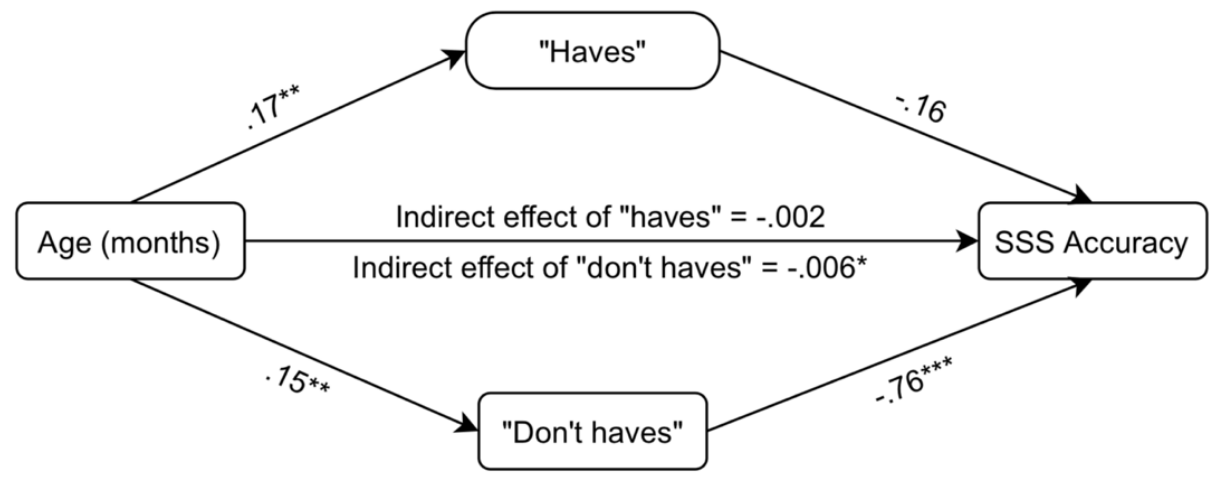

Figure 5. Summary of the effects on SSS through "have" and "don't have" codes in participants' rationales. Paths are labeled with their beta coefficients. Asterisks represent significance at the $.05(*), .01(* *)$, and .001 levels $(* * *)$. 
In sum, although both "haves" and "don't haves" increased over development, SSS was significantly predicted only by the number of references children made to "not having," not by the number of references children made to "having." This asymmetry was also evident in children's SSS accuracy. Finally, mediation models confirmed that “don't haves” partially mediated relations between age and SSS, and between age and SSS accuracy, unlike "haves".

\section{Discussion}

The present study explored the development of subjective social status (SSS). We aimed to replicate previous findings that SSS declines across the childhood years, and also to extend this research area by shedding initial light on possible cognitive mechanisms underlying SSS declines, and also by confirming that these shifts reflected developmental increases in SSS accuracy. We assessed four- to ten-year-old children's SSS judgments, as well as their openended rationales for these judgments. Results indicated that SSS declined over development, replicating previous work, and also that SSS accuracy improved over development as children less often overestimated their social status, confirming our predictions. Moreover, SSS and SSS accuracy both corresponded with children's consideration of what they do not have, but not with their consideration of what they do have, nor with the particular status cues they relied upon. Additionally, mediation models confirmed that "don't haves," but not "haves," accounted for age-related changes in SSS and SSS accuracy. Thus, rather than reflecting broad developmental declines in positive self-evaluations, or shifts in children's use of particular status cues, shifts in SSS may instead reflect shifts in social comparison. In particular, children increasingly "compare upward" and consider what they do not have to estimate their family's status. 


\section{Developmental shifts in SSS and SSS accuracy}

This study replicated prior research showing that young children's SSS is near ceiling (Mandalaywala, Tai, \& Rhodes, 2020) but declines over development (Amir et al., 2019). However, these studies were not able to assess the accuracy of children's social status judgments, leaving open the possibility that young children's high SSS judgments accurately reflected the socioeconomic status of the participants in these studies. In the present study, by collecting data on participants' objective relative social status, we were able to evaluate the accuracy of children's SSS judgments. Results confirmed our hypothesis that young children tend to overestimate their SSS, but that their accuracy improves over development. ${ }^{6}$

One limitation of this study was the relatively high socioeconomic status of our sample. The Median Household Income of our sample fell in the \$100,000-\$150,000 range, making it significantly higher than the MHI of families with children in the U.S. $(\$ 78,000)$, though in line with the MHI of families in the state where the study took place $(\$ 111,000)$. This median income range was also consistent with prior research on early adolescents' SSS (10- to 12-year-olds, Mistry et al., 2015). Importantly, we were primarily interested in relative social status, and our sample represented a roughly even mix of children who were in the upper versus lower half of the income distribution in their neighborhoods. Nevertheless, future research with more children from lower-income backgrounds would deeply enrich this research area, especially given our finding that thinking about what one does not have may play a key role in children's SSS.

The study was also conducted in the context of the United States, where there is particularly severe wealth inequality (Zucman, 2019). Although developmental declines in SSS have been found across diverse cultures including India, Argentina, and indigenous communities

\footnotetext{
${ }^{6}$ See Section 2g in the Supplementary Materials 2-for further evidence that these results truly reflect improvements in accuracy rather than shifts toward SSS underestimation.
} 
in Ecuador (Amir et al., 2019), there are nevertheless several ways in which this cultural context may have shaped our results. For example, children in the US have more positive self-regard than children in some other countries (e.g., China; Wang, 2004) and also grow up in more socioeconomically segregated neighborhoods (Loh, Coes, \& Buthe, 2020), potentially reducing opportunities for social comparison. Thus, we remind readers that aspects of our results may be specific to our sample rather than universal (following recommendations by DeJesus et al., 2019, among others). Future research should explore how cultural context shapes the development of SSS, and should consider longitudinal designs in order to capture these processes as they unfold.

The finding that young children tended to overestimate their social status has important implications for early social attitudes (see discussion in Mandalaywala et al., 2020) and identity development. For example, children who are from low-status groups themselves nevertheless show some social preferences for high-status groups (for reviews, see Dunham et al., 2014; Shutts et al., 2011). One common interpretation of this phenomenon is that low-status children's ingroup-based preferences are not strong enough to overpower their status-based preferences, with ingroup-based preferences and status-based preferences representing distinct processes that pull children's preferences in different directions (e.g., Dunham, Baron, \& Banaji, 2008; Newheiser et al., 2014). Our results suggest an alternative possible interpretation: Children from low-status groups may mistakenly view themselves as high-status, and therefore their statusbased preferences may partially reflect ingroup-based preferences. Indeed, research shows that young children of color mistakenly self-identify as white, doing so more often than white children mistake their racial identity (Corenblum \& Annis, 1993; Cramer \& Anderson, 2003). This error may reflect young children's awareness of intergroup differences in status, in conjunction with a view of themselves as high-status. Future research should explore how young 
children's inflated view of their status informs prejudice development and identity development.

\section{Cognitive mechanisms underlying SSS declines}

By probing children's open-ended rationales for their social status judgments, we shed initial light on the reasoning children employ to determine their family's social status. This approach follows prior research using open-ended explanations from children as young as three years old as a window into their reasoning (e.g., Hickling \& Wellman, 2001; Legare, Wellman, \& Gelman, 2009; Rhodes, 2014). Although one might be skeptical about the cognitive meaningfulness of young children's explanations, empirical and conceptual work suggests that open-ended explanation and rationale measures are cognitively revealing even among young children (see Wellman, 2011 for a review). Notably, children may be better at explaining physical and social phenomena than explaining their own reasoning or beliefs (see Legare, Wellman, \& Gelman, 2009 for a discussion). Although superficially, our question ("why do you think your family is there?") asked children about their own reasoning, children's responses universally focused on their families ("because we/they...") rather than on their own thinking (“because I...”); we merely interpreted these responses as indicative of children's reasoning. Thus, our measure was similar to other rationale questions used with young children ("Why do you think that is?" Cimpian \& Markman, 2009, "Why do you think Lerato got sick?" Legare \& Gelman, 2008), and different from truly metacognitive questions on which children's reasoning is poor and their answers less cognitively revealing (e.g., "How well do you understand how an [object] works?” Rozenblit \& Keil, 2002; "Did everything [in the provided text] make sense?" Markman, 1979). In sum, we believe that children's rationales meaningfully revealed the 
reasoning they employed rather than being post-hoc justifications of their judgments.

Nevertheless, future work should seek to extend these findings through additional measures.

We had three competing hypotheses about the mechanisms that might underlie young children's SSS overestimates: If young children overestimate their SSS because they broadly view themselves positively, then their rationales should have included more "haves" and fewer "don't haves," and shifts in these variables should have predicted shifts in SSS. If young children overestimate their SSS because they rely on different cues to ascertain their social status, then these cues should have shifted over development and predicted shifts in SSS. Finally, if young children overestimate their SSS because of a tendency to not engage in upward social comparison, then then their rationales should have included fewer "don't haves," and shifts (only) in "don't haves" should have predicted shifts in SSS.

We found little support for the possibility that SSS overestimates reflect young children's overall positive view of themselves, or “wishful thinking." Children's rationales included both more "haves" and more "have nots" over development, there were no significant shifts in the ratio between these variables, the number of "haves" did not significantly predict SSS judgments overall, and "haves" did not mediate the relation between age and SSS or between age and SSS accuracy - all results that we would have expected to see if declines in SSS reflected declines in the overall positivity of children's self-evaluations. We also found little support for the possibility that shifts in SSS reflect shifts in the particular status cues children use. Although children used a greater variety of status cues over development, and increasingly relied on neighborhood as a status cue in particular, neither of these shifts predicted shifts in SSS.

Critically, we did find robust evidence for the possibility that SSS judgments reflect the extent to which children consider what they do not have. The number of times children referred 
to not having something significantly predicted their SSS judgments, and also significantly predicted the accuracy of these judgments. In contrast, the number of times children referred to having something did not significantly predict either of these outcomes. Indeed, "don't haves" partially mediated the relation between age and SSS, and between age and SSS accuracy, while “haves” did not. Thus, “don’t haves” may play a unique role in informing children’s SSS, relative to "haves." These results align with our prediction that children's SSS overestimates may reflect a tendency to not engage in upward social comparison, as the task asked children to evaluate themselves relative to others in their neighborhoods. The finding that children increasingly reference their neighborhoods also aligns with the conclusion that children increasingly engage in social comparison over development, as these codes captured reflections on how houses and lifestyles compared to others' in their neighborhoods.

\section{Young children tend to ignore what they do not have}

The finding that children's SSS reflects their neglect to consider what they do not have relates to several adjacent literatures. First, children tend to avoid upward social comparison in other domains (Boggiano \& Ruble, 1979; Ruble et al., 1980, 1994). For example, when evaluating their own competence, children tend to ignore their peers' superior performance (Boggiano \& Ruble, 1979; Ruble et al., 1980) and overestimate their own future performance (Cimpian, 2010; Schneider, 1998; Smiley \& Dweck, 1994). The social comparison literature has thus far largely focused on self-evaluations of competence; we examine self-evaluations of status and suggest that similar processes may be at play.

Children's early tendency not to engage in upward social comparison seems, at first glance, to contradict research on inequity aversion in childhood. Multiple studies have found that 
preschoolers do spontaneously notice when others receive less or more than them (Birch \& Billman, 1986; Kirkland et al., 2021a; LoBue et al., 2010),will sometimes donate resources to low-resource peers (Kirkland et al., 2021b) or sacrifice resources to maintain equal resource distributions (Blake \& McAuliffe, 2011; McAuliffe, et al., 2017). However, we believe that young children's aversion to being at a disadvantage, as demonstrated in inequity aversion research, may directly motivate children's neglect to consider what they do not have. Children's immunity to what they do not have may serve as buffer for them against this aversive scenario. Importantly, although our results suggest that young children tend not to engage in upward social comparison, our results do not suggest why this is the case. This tendency might reflect an early cognitive bias, a lack of knowledge about what one does not have, or feedback from children's environments (for discussions, see Cimpian, 2017; Magid \& Schulz, 2015; Thomaes, et al., 2017). One possibility is that upward social comparisons require more advanced cognitive abilities than downward social comparisons. After all, what one does not have is inherently more abstract than what one does have. The abstract upward social comparisons may even require counterfactual reasoning (i.e., understanding that if one were to have $\mathrm{x}$, one would be higher-status), which might present executive demands, requiring children to inhibit their knowledge of the real world (see Beck, 2016 for discussion). Philosophical work has deemed this particular sort of counterfactual reasoning "causation by omission" (Beebee, 2004; McGrath, 2005), and has pointed out that causation by omission (e.g., $\mathrm{x}$ is the case because not-y) is counterintuitive compared to traditional causal explanations (e.g., $\mathrm{x}$ is the case because of $\mathrm{y}$ ). Thus, it is possible that incorporating “don't haves" into one's SSS is cognitively challenging, and that young children's difficulty with doing so reflects their cognitive limitations. 
Another possibility is that young children simply lack knowledge about what others have that they do not, and therefore lack the background knowledge required to engage in social comparison. Information about what one does have is always more accessible than information about what one does not have. This is especially true given American socioeconomic segregation in which most low-income people live in low-income communities (Loh, Coes, \& Buthe, 2020), and thus may not have access to the information necessary to compare upward. As children grow older, they may gain information about what others have, and the value of what others have).

An final possibility is children's tendency not to incorporate "don't haves" into their SSS reflects their environments, such as parental messages and cultural values. Cimpian (2017) has argued that children's optimistic self-evaluations of their abilities reflect the fact that children's environments tend to emphasize positivity, encourage self-congratulatory behavior, and avoid formal evaluative feedback. Children's environments might similarly promote optimistic selfevaluations of status, by encouraging youthful bragging about belongings or avoiding discussions of what cannot be provided. Future research should investigate the cognitive and environmental factors underlying this early tendency.

\section{Conclusion}

In sum, we find that children's subjective social status (SSS) decreases across childhood as children less frequently overestimate their social status. Our results suggest that this trend reflects children's growing tendency to "compare upward" and consider what they do not have when assessing their status. Future research should continue to explore children's developing SSS and its important downstream consequences for early self-evaluation, social attitudes, and wellbeing. 


\section{References}

Ahl, R. E., \& Dunham, Y. (2019). “Wealth Makes Many Friends”: Children Expect More Giving From Resource-Rich Than Resource-Poor Individuals. Child Development, 90(2), 524543.

Ahl, R. E., Duong, S., \& Dunham, Y. (2019). Children employ wealth cues when predicting others' sharing. Developmental Psychology, 55(2), 303.

Amir, D., Valeggia, C., Srinivasan, M., Sugiyama, L. S., \& Dunham, Y. (2019). Measuring subjective social status in children of diverse societies. PloS One, 14(12), e0226550.

Anderson, C., Kraus, M. W., Galinsky, A. D., \& Keltner, D. (2012). The local-ladder effect: Social status and subjective well-being. Psychological Science, 23(7), 764-771.

Beebee, H. (2004). Causing and Nothingness. In J. Collins, N. Hall, and L.A. Paul (Eds.) Causation and Counterfactuals (pp. 291-308). MIT Press.

Bigler, R. S., Averhart, C. J., \& Liben, L. S. (2003). Race and the workforce: Occupational status, aspirations, and stereotyping among African American children. Developmental Psychology, 39(3), 572.

Birch, L. L., \& Billman, J. (1986). Preschool children's food sharing with friends and acquaintances. Child Development, 387-395.

Boggiano, A. K., \& Ruble, D. N. (1979). Competence and the overjustification effect: A developmental study. Journal of Personality and Social Psychology, 37(9), 1462.

Brummelman, E., \& Thomaes, S. (2017). How children construct views of themselves: A socialdevelopmental perspective. Child Development, 88(6), 1763-1773.

Cheung, F., \& Lucas, R. E. (2016). Income inequality is associated with stronger social 
comparison effects: The effect of relative income on life satisfaction. Journal of Personality and Social Psychology, 110(2), 332.

Cimpian, A. (2010). The impact of generic language about ability on children's achievement motivation. Developmental Psychology, 46(5), 1333-1340.

Cimpian, A. (2017). Early reasoning about competence is not irrationally optimistic, nor does it stem from inadequate cognitive representations. In A. J. Elliot, C. S. Dweck, \& D. S. Yeager (Eds.), Handbook of competence and motivation: Theory and application (2nd ed., pp. 387-407). New York, NY: Guilford.

Cimpian, A., \& Markman, E. M. (2009). Information learned from generic language becomes central to children's biological concepts: Evidence from their open-ended explanations. Cognition, 113(1), 14-25.

Corenblum, B., \& Annis, R. C. (1993). Development of racial identity in minority and majority children: An affect discrepancy model. Canadian Journal of Behavioural Science, 25(4), 499.

Cramer, P., \& Anderson, G. (2003). Ethnic/racial attitudes and self-identification of Black Jamaican and White New England children. Journal of Cross-Cultural Psychology, 34(4), 395-416.

Cvencek, D., Greenwald, A. G., \& Meltzoff, A. N. (2016). Implicit measures for preschool children confirm self-esteem's role in maintaining a balanced identity. Journal of Experimental Social Psychology, 62, 50-57.

DeJesus, J. M., Callanan, M. A., Solis, G., \& Gelman, S. A. (2019). Generic language in scientific communication. Proceedings of the National Academy of Sciences, 116(37), $18370-18377$. 
Dunham, Y., Newheiser, A. K., Hoosain, L., Merrill, A., \& Olson, K. R. (2014). From a different vantage: Intergroup attitudes among children from low-and intermediate-status racial groups. Social Cognition, 32(1), 1-21.

Dunham, Y., Baron, A. S., \& Banaji, M. R. (2008). The development of implicit intergroup cognition. Trends in Cognitive Sciences, 12(7), 248-253.

Enesco, I., \& Navarro, A. (2003). The development of the conception of socioeconomic mobility in children from Mexico and Spain. The Journal of Genetic Psychology, 164(3), 293-317.

Fritz, M. S., \& MacKinnon, D. P. (2007). Required sample size to detect the mediated effect. Psychological Science, 18(3), 233-239.

Goodman, E., Adler, N. E., Kawachi, I., Frazier, A. L., Huang, B., \& Colditz, G. A. (2001). Adolescents' perceptions of social status: development and evaluation of a new indicator. Pediatrics, $108(2)$, e31-e31.

Goodman, E., Maxwell, S., Malspeis, S., \& Adler, N. (2015). Developmental trajectories of subjective social status. Pediatrics, 136(3), e633-e640.

Greitemeyer, T., \& Sagioglou, C. (2016). Subjective socioeconomic status causes aggression: A test of the theory of social deprivation. Journal of Personality and Social Psychology, 111(2), 178.

Harter, S. (2012). The construction of the self: Developmental and sociocultural foundations (2nd ed.). New York: Guilford Press.

Heck, I. A., Kushnir, T., \& Kinzler, K. (2021). Social sampling: Children track social choices to reason about status hierarchies. In press at Journal of Experimental Psychology: General. https://doi.org/10.1037/xge0001008

Hickling, A. K., \& Wellman, H. M. (2001). The emergence of children's causal explanations and 
theories: Evidence from everyday conversation. Developmental Psychology, 37(5), 668.

Hoebel, J., Maske, U. E., Zeeb, H., \& Lampert, T. (2017). Social inequalities and depressive symptoms in adults: the role of objective and subjective socioeconomic status. PloS One, 12(1), e0169764.

Horwitz, S. R., Shutts, K., \& Olson, K. R. (2014). Social class differences produce social group preferences. Developmental Science, 17(6), 991-1002.

Jackman, M. R., \& Jackman, R. W. (1973). An interpretation of the relation between objective and subjective social status. American Sociological Review, 569-582.

Kids Count Data Center, a project of the Annie E. Casey Foundation \& Center for the Study of Social Policy. Median Family Income among Households with Children by Family Nativity. Retrieved from datacenter.kidscount.org/data/tables/123-median-familyincome-among-households-with-children-by-family-nativity

Kirkland, K., Jetten, J., \& Nielsen, M. (2020). Economic inequality affects young children's prosocial decision making. British Journal of Developmental Psychology, 38, 512-528.

Kirkland, K., Jetten, J., Wilks, M. \& Nielsen, M. (2021a). How economic inequality affects prosocial behavior in children across development. Journal of Experimental Child Psychology, 201, 105202

Kirkland, K., Jetten, J., Wilks, M. \& Nielsen, M. (2021b). Children's experience of economic inequality: How earning position influences prosocial behavior. Cognitive Development, $58,101043$.

Leahy, R. L. (1981). The development of the conception of economic inequality. I. Descriptions and comparisons of rich and poor people. Child Development, 523-532.

Leahy, R. L. (1983). Development of the conception of economic inequality: II. Explanations, 
justifications, and concepts of social mobility and change. Developmental Psychology, 19(1), 111.

Legare, C. H., \& Gelman, S. A. (2008). Bewitchment, biology, or both: The co-existence of natural and supernatural explanatory frameworks across development. Cognitive Science, 32(4), 607-642.

Legare, C. H., Wellman, H. M., \& Gelman, S. A. (2009). Evidence for an explanation advantage in naïve biological reasoning. Cognitive Psychology, 58(2), 177-194.

Levin, K. A., Torsheim, T., Vollebergh, W., Richter, M., Davies, C. A., Schnohr, C. W., \& Currie, C. (2011). National income and income inequality, family affluence and life satisfaction among 13 year old boys and girls: A multilevel study in 35 countries. Social Indicators Research, 104(2), 179-194.

Li, V., Spitzer, B., \& Olson, K. R. (2014). Preschoolers reduce inequality while favoring individuals with more. Child Development, 85(3), 1123-1133.

LoBue, V., Nishida, T., Chiong, C., DeLoache, J. S., \& Haidt, J. (2011). When getting something good is bad: Even three-year-olds react to inequality. Social Development, 20(1), 154170.

Luttmer, E. F. (2005). Neighbors as negatives: Relative earnings and well-being. The Quarterly Journal of Economics, 120(3), 963-1002.

Magid, R., \& Schulz, L. (2015). Quit while you're ahead: Preschoolers' persistence and willingness to accept challenges are affected by social comparison. In CogSci.

Mandalaywala, T. M., Tai, C., \& Rhodes, M. (2020). Children's use of race and gender as cues to social status. PloS one, 15(6), e0234398.

Markman, E. M. (1979). Realizing that you don't understand: Elementary school children's 
awareness of inconsistencies. Child Development, 643-655.

Marmot, M. (2004). Status syndrome. Significance, 1(4), 150-154.

Martin-Storey, A., Marcellin, S., Purtell, K. M., Tougas, A. M., \& Lessard, A. (2018). “It's about having money, but also happiness:” A qualitative investigation of how adolescents understand subjective status in themselves and others. Journal of Adolescence, 68, 198206.

McAuliffe, K., Blake, P. R., Steinbeis, N., \& Warneken, F. (2017). The developmental foundations of human fairness. Nature Human Behaviour, 1(2), 1-9.

Mistry, R. S., Brown, C. S., White, E. S., Chow, K. A., \& Gillen-O’Neel, C. (2015). Elementary School Children's Reasoning About Social Class: A Mixed-Methods Study. Child Development, 86(5), 1653-1671.

Mookherjee, H. N., \& Hogan, H. W. (1981). Class consciousness among young rural children. The Journal of Social Psychology, 114(1), 91-98.

Newheiser, A. K., Dunham, Y., Merrill, A., Hoosain, L., \& Olson, K. R. (2014). Preference for high status predicts implicit outgroup bias among children from low-status groups. Developmental Psychology, 50(4), 1081.

Olson, K. R., Shutts, K., Kinzler, K. D., \& Weisman, K. G. (2012). Children associate racial groups with wealth: Evidence from South Africa. Child Development, 83(6), 1884-1899.

Pomerantz, E. M., Ruble, D. N., Frey, K. S., \& Greulich, F. (1995). Meeting goals and confronting conflict: Children's changing perceptions of social comparison. Child Development, 66(3), 723-738.

Quon, E. C., \& McGrath, J. J. (2015). Community, family, and subjective socioeconomic status: Relative status and adolescent health. Health Psychology, 34(6), 591. 
Ramsey, P. G. (1991). Young Children's Awareness and Understanding of Social Class Differences. Journal of Genetic Psychology, 152(1), 71-82.

Rauscher, E., Friedline, T., \& Banerjee, M. (2017). We're not rich, but we're definitely not poor: Young children's conceptions of social class. Children and Youth Services Review, 83, $101-111$.

Rhodes, M. (2014). Children's explanations as a window into their intuitive theories of the social world. Cognitive Science, 38(8), 1687-1697.

Rhodes, M., \& Brickman, D. (2008). Preschoolers' responses to social comparisons involving relative failure. Psychological Science, 19(10), 968-972.

Rivenbark, J. G., Copeland, W. E., Davisson, E. K., Gassman-Pines, A., Hoyle, R. H., Piontak, J. R., \& Odgers, C. L. (2019). Perceived social status and mental health among young adolescents: Evidence from census data to cellphones. Developmental Psychology, 55(3), 574.

Rozenblit, L., \& Keil, F. (2002). The misunderstood limits of folk science: An illusion of explanatory depth. Cognitive Science, 26(5), 521-562.

Ruble, D. N., Boggiano, A. K., Feldman, N. S., \& Loebl, J. H. (1980). Developmental analysis of the role of social comparison in self-evaluation. Developmental Psychology, 16(2), 105.

Ruble, D. N., Eisenberg, R., \& Higgins, E. T. (1994). Developmental changes in achievement evaluation: Motivational implications of self-other differences. Child Development, 65(4), 1095-1110.

Ruble, D. N., Grosovsky, E. H., Frey, K. S., \& Cohen, R. (1992). Developmental changes in competence assessment. Achievement and motivation: A social-developmental perspective, 138-164. 
Saegert, S. C., Adler, N. E., Bullock, H. E., Cauce, A. M., Liu, W. M., \& Wyche, K. F. (2006).

APA Task Force on socioeconomic status (SES). Retrieved from http://www.apa.org/pi/ses/resources/publications/task-force-2006.pdf

Schneider, W. (1998). Performance prediction in young children: Effects of skill, metacognition and wishful thinking. Developmental Science, 1(2), 291-297.

Shutts, K., Kinzler, K. D., Katz, R. C., Tredoux, C., \& Spelke, E. S. (2011). Race preferences in children: Insights from South Africa. Developmental Science, 14(6), 1283-1291.

Shutts, K., Brey, E. L., Dornbusch, L. A., Slywotzky, N., \& Olson, K. R. (2016). Children use wealth cues to evaluate others. PloS One, 11(3), e0149360.

Sigelman, C. K. (2012). Rich man, poor man: Developmental differences in attributions and perceptions. Journal of Experimental Child Psychology, 113(3), 415-429.

Singh-Manoux, A., Marmot, M. G., \& Adler, N. E. (2005). Does subjective social status predict health and change in health status better than objective status?. Psychosomatic Medicine, 67(6), 855-861.

Smiley, P. A., \& Dweck, C. S. (1994). Individual differences in achievement goals among young children. Child Development, 65(6), 1723-1743.

Thomaes, S., Brummelman, E., \& Sedikides, C. (2017). Why most children think well of themselves. Child Development, 88(6), 1873-1884.

Trzesniewski, K. H., Donnellan, M. B., \& Robins, R. W. (2013). Development of selfesteem. Self-Esteem, 60-79.

Wellman, H. M. (2011). Reinvigorating explanations for the study of early cognitive development. Child Development Perspectives, 5(1), 33-38.

Zucman, G. (2019). Global wealth inequality. Annual Review of Economics, 11, 109-138. 